\title{
Hyperchloremia-associated acute chronic kidney injury: beware of confounders!
}

\author{
Patrick M. Honore ${ }^{1 *}$, David De Bels ${ }^{1}$, Luc Kugener ${ }^{1}$, Sebastien Redant ${ }^{1}$, Rachid Attou ${ }^{1}$, Andrea Gallerani ${ }^{1}$ \\ and Herbert D. Spapen ${ }^{2}$
}

See related research by Oh et al., https://ccforum.biomedcentral.com/articles/10.1186/s13054-018-2216-5

We read with great interest the recent paper by $\mathrm{Oh}$ et al. [1] investigating the association between perioperative hyperchloremia and postoperative acute kidney injury (AKI) in a large population of postsurgical patients admitted to the intensive care unit (ICU). One of the conclusions was that a substantial perioperative increase in serum chloride levels may reflect a higher risk of AKI in patients with moderate-to-severe chronic kidney disease (CKD) [1].

The authors exemplified some thoughtful limitations of the study. However, when looking carefully at the patient characteristics in the different cohorts, we came across several risk factors for AKI that were more present in hyperchloremic than in normochloremic subjects. The hyperchloremia group received significantly more radiocontrast ( 52.8 vs $28.4 \% ; P<0.001)$, non-steroidal anti-inflammatory drugs (NSAIDs; 40.2 vs $35.9 \% ; P=0.001$ ), and diuretics, including mannitol and furosemide (69.3 vs $56.0 \% ; P<0.001)$. Also, patients who developed hyperchloremia had more severe shock as indicated by a higher need for inotropic and vasopressor support ( 87.2 vs $70.1 \% ; P<0.001$ ) and more frequently underwent emergency surgery (17.5 vs $12.3 \%$; $P<0.001$ ). Contrast agents [2], NSAIDs [3], mannitol [4], and furosemide [5] are all associated with a potential deterioration of renal function in ICU patients and particularly in those with underlying CKD. In addition, emergency surgery and shock may markedly increase the incidence of AKI in the perioperative period. Taken together, the patient groups with and without hyperchloremia were not adequately balanced with regard to specific and independent AKI risk factors.

* Correspondence: Patrick.Honore@CHU-Brugmann.be

${ }^{1}$ ICU Department, Centre Hospitalier Universitaire Brugmann, Brugmann University Hospital, 4 Place Van Gehuchtenplein, 1020 Brussels, Belgium Full list of author information is available at the end of the article

\author{
Abbreviations \\ AKI: Acute kidney injury; CKD: Chronic kidney disease; ICU: Intensive care \\ unit; NSAIDs: Non-steroidal anti-inflammatory drugs
}

\author{
Acknowledgements \\ None. \\ Funding \\ None. \\ Availability of data and materials \\ Not applicable.
}

\begin{abstract}
Authors' contributions
PMH and HDS designed the paper. All authors participated in drafting and reviewing. All authors read and approved the final version of the manuscript.
\end{abstract}

Ethics approval and consent to participate

Not applicable.

\section{Consent for publication \\ Not applicable.}

\section{Competing interests}

The authors declare that they have no competing interests.

\section{Publisher's Note}

Springer Nature remains neutral with regard to jurisdictional claims in published maps and institutional affiliations.

\begin{abstract}
Author details
'ICU Department, Centre Hospitalier Universitaire Brugmann, Brugmann University Hospital, 4 Place Van Gehuchtenplein, 1020 Brussels, Belgium. ${ }^{2}$ Ageing \& Pathology Research Group, Vrije Universiteit Brussel, Brussels, Belgium.
\end{abstract}

Received: 13 November 2018 Accepted: 6 December 2018 Published online: 10 January 2019

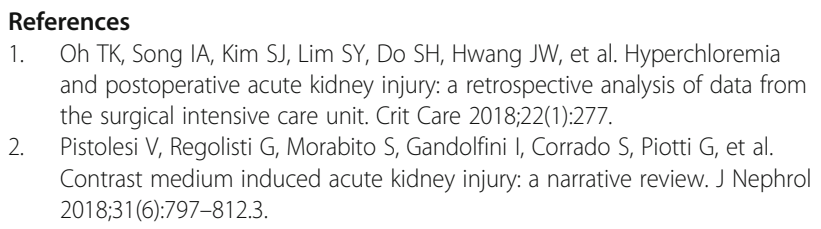

2. Pistolesi V, Regolisti G, Morabito S, Gandolfini I, Corrado S, Piotti G, et al. Contrast medium induced acute kidney injury: a narrative review. J Nephrol 2018;31(6):797-812.3. 
3. Zhang X, Donnan PT, Bell S, Guthrie B. Non-steroidal anti-inflammatory drug induced acute kidney injury in the community dwelling general population and people with chronic kidney disease: systematic review and meta-analysis. BMC Nephrol 2017;18(1):256.

4. Fang L, You H, Chen B, Xu Z, Gao L, Liu J, et al. Mannitol is an independent risk factor of acute kidney injury after cerebral trauma: a case-control study. Ren Fail 2010;32(6):673-9.

5. Ho KM, Power BM. Benefits and risks of furosemide in acute kidney injury. Anaesthesia 2010;65(3):283-93. 